\title{
Societal Panorama of Power: Emancipation of Women or Threat?
}

\author{
Hadley Quadros \\ Department of Sociology, St. Andrew's College (Affiliated to University of Mumbai) \\ Bandra (West), Mumbai, India. \\ Vatika Sibal \\ Associate Professor, Department of Sociology, St. Andrew's College (Affiliated to University of \\ Mumbai), Bandra (West), Mumbai, India.
}

\begin{abstract}
The pandemic has brought the world to a standstill. The dearth to survive in the wake of devastation has made humans adapt to the new normal which was never experienced but now has become a protocol. The phrase which was the tagline for global partnerships 'united we stand, divided we fall' has now transformed into 'divided we stand, united we fall', as a claim to survive this pandemic. In India where the virus has claimed the maximum toll of human lives, continues to fight various battles to survive. On one side, the health workers, doctors, police are risking their lives so that the common man may not be affected while on the other hand, people within the houses are falling victims to domestic and sexual abuse. In the light of the pandemic that has claimed lives as well as loss of employment; the struggle to survive has hit a different tone especially among the lower and the middle income families. The frustration of losing a job is vented on the family members as there remains no source of income to support the family. This article tries to unearth the existing social problems of abuse among men and women at large especially during the pandemic. The principle of resistance is understood in the sexual division of labour where individuals are now trying to be communicating with the outside world while remaining at home.
\end{abstract}

Keyword: pandemic, abuse, representations, hegemony, survival

People all around the world consume media products on a daily basis. Media bears a profound role in our lives and helps shape our ideas about social, cultural, political and economic issues. Media is peppered with messages that reach audiences far and wide. These messages contribute to our perceptions of the world, and in relation to this study, our perception about women. Women have made great strides in all aspects of life, but their depiction on-screen has been stuck to patriarchal stereotypes and normative ideologies that do not reflect reality. The media's use of genre films has perpetuated such depictions.

Bulbbul, Ajji and Hellaro are three representations of films where an attempt is made salient the dominant messages that these films circulate with respect to women. Through a visual analysis of the semiotics of women within films, it has been found that while some genres portray women as independent, powerful and agentive individuals, many still succumb to patriarchal constructions. Positive images of women outside the action-adventure genre are 
relatively scarce. Though we have come far in our depictions, we still have a long way to go before women are represented in a more realistic manner.

Structural agencies like Patriarchy and capitalism controls media that authenticates the representation of women as subordinates. The recent debate of mass media vis-a-vis gender produces much more complex understandings of the cultural dimensions of power and equality, and more specifically feminist analyses of the media, culture and society. With the proliferation of 'women's genres' -- soap operas, melodramas, women's magazines and so on -women have emerged as important consumers of mass entertainment. The media also set the agenda for public opinion by selecting themes, items and points of view that tend to reinforce the patriarchal culture. But, the media simply does not reflect the social reality and conditions our values, attitudes and behaviour. They constitute only one side of the construction of women's marginality in culture. The relationship between the media and reality is, however, dialectical.

Culture is not a static system, but an ever-evolving process that constantly changes to accommodate emergent alternative and oppositional meanings, values and practices. Media, particularly print and broadcasting media (television and radio), do provide some space for the construction of new meanings and images. Although the progressive discourse is often co-opted in media and re-constructed again to establish the hegemony of dominant social classes and reproduce gender relations. Obviously, women's groups and media professionals challenge them in the context of a larger system of patriarchy and capitalism that controls media and subordinate women. Feminist activists and academicians, therefore, analyze the negative portrayal of women in media.

Films are believed to be the opium of the Indian masses as people rely on this medium to help them escape to a world of fantasy. In a very explicit way, cinema has shaped the cultural, social and political values of the people of this country. While, the other forms of cinema are also important when it comes to the representation of women, restricting to popular cinema is the core concern of the paper. The interest in films taken by feminists stems from concern about the under-representation and misrepresentation of women in cinema. It adopts a critical approach towards gender bias on celluloid. The feminist approach to cinema asks a few pertinent questions like how women are represented on screen, how women's issues are treated in cinema, what does feminism mean to film-makers, how does the feminist agenda manifest on screen, how is the women character positioned vis-a-vis the male character and what is the role of women film-makers and women writers in depicting women's issues through cinema.

Feminist critique of cinema has helped to view the reality presented by cinema in a different way and thus has contributed significantly to the discipline of media studies as well as film studies. Certain underlying aspects of a popular medium can only be brought to the surface by criticism, scrutiny and introspection and feminists have attempted to do it with cinema as well as with other fields of study and practice. The links between Women's Studies and Cinema are evident. After the women's movement, the field of women's studies has allied with almost every discipline to provide an alternative perspective of knowledge and reality as viewed by the practitioners and academia of the discipline. The feminist theory took up a distinct stance in relation to the objectification, exclusion and silence of women in cinematic narratives. It also evaluated the stereotyping of female characters in cinema. For eg: In 'Visual Pleasure and Narrative Cinema' (Laura Mulvey, 1975), the male character was identified as the driver of the film's narrative, the character followed by the camera. The female character served as a spectacle to provide pleasure to the male spectator. It has been seen to be influenced by patriarchal values. Thus feminist theory in its critique of films incorporated the valorisation of women's experiences thereby posing a challenge to gender hierarchy as well as opening up new realms for a post-gendered future. 
We tell our children stories of 'daakus' who steal unsuspecting children by offering them chocolates. We instruct them to not stray too far away from home while playing outside. What we fail to warn them of is danger within the house. India, as a culture, is no stranger to violence at home, particularly domestic violence. And this heinous exploitation continues to prevail because it is considered a marital or domestic issue, not a societal one. However, sexual violence is different. Not by nature of severity; different forms of violence are not quantitatively comparable. But the sexual nature of sexual violence makes it different - invasive, almost personal. And the systems in place in Indian society serve only to exacerbate the adverse nature of such a violation. Sexual violence typically stems from the real and/or perceived inequality between men and women, which is then influenced by cultural factors and values.

The existing rape culture in India, which is glorified in media, reinstates the function of women as sexual objects. Sexual violation of said object becomes the worst means of humiliation especially for a woman. This leads to the most powerful means of performative dominance for a man. And this sexual violence may not necessarily be active. Passive, but blatant use of means like rape threats to women and their families, the sexual degradation or slut-shaming of women, and moral policing of women and sexual and non-sexual aspects of their lives, among others, also constitute violence. Media refers to rape culture to any environment where rape is prevalent, which normalizes sexual violence against women and excuses it through media and popular culture. Sexual violence includes aspects of control, power, domination and humiliation. While the act in itself may not be sexually gratifying for the perpetrators, the meaning attributed to power for them may often override the sexual goals of the act itself. From a very young age, girls are told for their own good to protect their virginity, because boys will be boys and will want to take advantage of them. They are told to cover up because it's in the nature of men to stare and therefore, it being natural for them to feel sexually aroused, and thereafter be sexually violent.

The responsibility for safety lies on women and not on the men threatening it. The problem is not addressed as families never tell their sons, brothers, and husbands not to take advantage of women, or to not stare and the media reinstates that too. Men are apparently born sexually deviant and so, women must learn to protect themselves - an argument of convenience made by men to shirk all responsibility, and by some women who are victims of their systems, taught to cling on to every word that spills out of a man's mouth. Therefore moral policing of women never ceases. This is clearly depicted in the two films Bulbbul and Ajji where importance is placed on the sexual purity and sanctity of women, as a woman to be violated in any way become her ultimate fear (Guptan, 2020). And fear is but the fuel to power (Makhija, 2017). This begs a question - If the culture as a whole was to reduce the importance it gave to the sexual purity of a woman, could it be possible that threats of sexual violence against women and those perpetuating them would lose their power? Additionally, the humiliation associated with sexual violence and the onus of getting violated is dumped on the victim. In the context of Hellaro, the celebration of womanhood through dance is criticized as women are restricted to their personal and cultural space which is inside the house (Shah, 2019). The dichotomy of nature vs nurture is enshrined in the patriarchal society, where men used to go out and hunt and provide for the family, while the women were expected to be inside the house and take care of the family. Although society has passed through different development phase in the different circles of life; the life of women still remains to linger in the shadow of men who continue to silence them with their hegemonic identity.

Even consensual sex is not spoken about openly and directly in Indian families. One can only imagine how shameful it could feel to be violated in a way, which even when done consensually is a taboo. Rape within the institution of marriage is not even considered an offence, because we have normalized and even romanticized the complete body-and soul possession of a woman by her husband. Akin to how children are never warned of danger within the house, women are 
not warned of dangers within a marriage - both institutions that feign safety, but have repeatedly failed us. Men too are victims of sexual violence, almost always to other men. Male children in particular fall prey to undiagnosed pedophilia and sexual deviance, some of which may be psychopathological, while others a warped need for power, dominance and control. The Indian culture and media refuse to acknowledge that boys can be raped. Therefore, for a victim of such violence, the shame is double-fold because he is denied of his trauma and unable to speak of it. This endows the perpetrator with an additional sense of power and the audacity to repeat the offense. Given that sexual violence against women and children was already highly prevalent and has aggravated during the COVID-19 pandemic.

Evidence also suggests that rates of sexual violence typically increase during states of emergency or unrest, as during a natural disaster, active conflict or even health crisis. During any pandemic or disease outbreak, almost all response efforts are focused on controlling the disease. This diverts the resources allocated to sexual violence prevention, into contingency efforts in managing a disease outbreak. But what about the disease that is nurtured in our families? As long as the problem within the family is not addressed by virtue of respect and acceptance, the fight towards the pandemic will remain a monotonous struggle satisfying the ego, the seed of destruction and despair.

\section{Conclusion}

Yes, the pandemic is a pressing issue. Yes, the country is undergoing a massive economic crisis. Yes, people are hungry, unemployed, and unwell. Yes, violence appears to be the least of the problems. The pandemic appears to be the biggest issue at hand because the news and media channels are covering it extensively. Any information we read, watch or listen to pertains to the death count and active cases of COVID-19. If the media were to cover the cases of sexual violence at home with as much rigour, we would be shocked to our very roots at the number of children and women being violated at the very moment that we are hearing of it. One may argue that the disease is infectious. Adversities cannot be quantitatively compared. Over centuries there have been more women and children who have succumbed to sexual violence than any media report, research paper, database, or tracking website could possibly fathom. It is a disease in itself, more insidious and infectious than any virus could ever be, sneaking up on you in spaces you felt previously safe in. One indulges in comparison not because the kinds of destruction wreaked by both these diseases are comparable. Rather, one's attention is drawn to qualities that can be attributed to both. The virus kills those who are elderly and have comorbid conditions, and leaves the others sick and recovering with a hope for future immunity. Sexual violence offers no immunity. It repeats, kills and takes the life out of its victims in ways that there is often no returning from. These survivors are living that nightmare day in and day out, while being stuck with the person/s hurting them, with no place and no one to call home. The trauma resulting from this period of crisis will not be easy to recover from. It will be irreversible in many ways, and possibly even generational. But what we can do, what is under our control is minimizing the damage that is currently being done. We cannot control a natural disaster, we can only cope. But violence, unlike a pandemic, is a human condition. We consciously choose it, and can therefore choose to consciously annihilate it. There are hundreds of thousands of people silently screaming and going unheard. They need our help; they need your help. Reach out, be kind.

\section{REFERENCES}

[1]. Guptan, A. D. (Director). (2020). Bulbbul [Motion Picture].

[2]. Herman, Judith L..1992. "Complex PTSD: A syndrome in survivors of prolonged and repeated trauma.”Journal of Traumatic Stress 5, no. 3 (July): 377-391.Herman, Judith L.. 1995. “Complex PTSD."

[3]. Lincoln, Y., and N. Denzin.2003. Turning Points In Qualitative Research. Walnut Creek CA: AltaMira Press. 
[4]. Makhija, D. (Director). (2017). Ajji [Motion Picture].

[5]. Onyango Monica, Kirsten Resnick, Alexandra Davis, and Rupal Shah R. .2019. "Gender-Based Violence Among Adolescent Girls and Young Women: A Neglected Consequence of the West African EbolaOutbreak." In Global Maternal and Child Health (Medical, Anthropological, and Public Health Perspectives), edited by D. Schwartz, J. Anoko, S. Abramowitz, 121-32. Cham: Springer.

[6]. Psychotraumatology, edited by George S. Everly Jr. and Jeffrey M. Lating, 87-100. Boston MA: Springer

[7]. Rai, Dipu. 2020. "Sexual Violence Pandemic In India: Rape Cases Doubled In Last 17 Years." India Today

[8]. Shah, A. (Director). (2019). Hellaro [Motion Picture]. 